\title{
A 5-year Study on Ectopic Pregnancy in North India
}

\author{
Dr. Jayati Nath ${ }^{1 *}$, Dr. Akshara Mishra ${ }^{2}$, Dr. Vaishali Verma ${ }^{3}$, Dr. Somya Gupta ${ }^{4}$ \\ ${ }^{1}$ Professor \& Head, Obstetrics \& Gynecology Haryana, India \\ ${ }^{2-4}$ PG Trainee, Ob Gyn, SGT Medical College, Gurugram, Haryana, India
}

\author{
DOI: $10.36348 /$ sijog.2021.v04i03.001
}

| Received: 17.02.2021 | Accepted: 02.03.2021 | Published: 05.03.2021

*Corresponding author: Dr. Jayati Nath

\section{Abstract}

Ectopic Pregnancy, a life jeopardizing emergency, can land in disaster, if the diagnosis is missed. Any woman in the reproductive age group presenting with vaginal bleeding and abdominal pain- the first suspicion should be ectopic. This was a hospital based retrospective cohort study of 5 years in Haryana, North India (3 Tertiary Care Centres)- to evaluate the incidence, patient profile, high risk factors, clinical presentation, diagnostic methods, treatment, outcome and complications of the same. Statistical analysis was done by MS Excel spread sheet using SPSS software 19.0 version. A total of 175 cases of ectopic pregnancy were diagnosed during the study period (Incidence of 1.521\%).Majority of the patients were in age group 21 to 30 years 101/175(57.71\%) with nulliparous being 60/175(34.28\%).Most important risk factors found were past history of miscarriage, pelvic surgery, tubal surgery and tubal ligation.75 \% patients presented with the classical triad of lower abdominal pain, amenorrhoea, and bleeding per vaginum. Clinical diagnosis was possible in $85.71 \%$ while $11.4 \%$ patients were ultrasonographically diagnosed. $96.7 \%$ were tubal ectopic gestations. Conservative expectant management was done in 2 patients, medical methotrexate therapy was given in 26 out of which 6 required surgery for failed therapy \& $84 \%$ were surgically managed. $54 \%$ required blood transfusion and there were no deaths. We conclude that identifying common risk factors and being ectopic minded will help clinicians in diagnosing and managing ectopic pregnancy at the earliest to reduce morbidity and mortality associated with the condition.

Key words: Amenorrhoea, Ectopic Pregnancy. Methotrexate, Miscarriage, Risk factors, Tubal pregnancy, Tubal surgery. Copyright ( $\odot 2021$ The Author(s): This is an open-access article distributed under the terms of the Creative Commons Attribution 4.0 International License (CC BY-NC 4.0) which permits unrestricted use, distribution, and reproduction in any medium for non-commercial use provided the original author and source are credited.

\section{INTRODUCTION}

Ectopic pregnancy is defined as the condition when the fertilized ovum gets implanted outside the uterine cavity. It is a recognized life-threatening emergency causing much maternal morbidity and if late diagnosed-mortality too. The overall incidence is approximately 1-3\% in most hospital based studies- but the incidence is showing a sharp upward trend in recent years [1-7].

As the classical triad of amenorrhoea, lower abdominal pain and bleeding per vaginum may not be seen in most of the patients, the diagnosis of ectopic pregnancy in a patient, unaware of being pregnant, may present with non-specific vague complaints or even with haemodynamic shock.

In India, the reported maternal mortality rate from ectopic pregnancy is approximately 3.5-7.1\% of all maternal mortality rates (MMR) $[1,8,9]$. This study was undertaken to evaluate all cases of ectopic pregnancy in last 5 years in 3 tertiary care centres of Haryana, North India to understand about the epidemiology, risk factors, clinical presentation, diagnosis, management and morbidities.

\section{MATERIALS AND METHODS}

- Study type: Hospital based, retrospective, cohort study

- Study period: 2015-2020

- Study duration: 5 years

All the case records from the Medical Record Department of patients of ectopic pregnancy during the five year period (September 2015-September 2020) in 3 tertiary care centres in Ambala and Gurugram of Haryana, North India. All the patient profile characteristics eg. socio-demographic variables- age, parity, high risk factors, mode of diagnosis, clinical presentation, management, complications, blood products transfusion were recorded and statistically 
Jayati Nath et al; Sch Int J Obstet Gynec, Mar. 2021; 4(3): 49-54

analysed including the incidence, high risk factors, materials and methods.

\section{STATISTICAL ANALYSIS}

All the data thus collected were entered into MS Excel sheet using SSPS version 19.0 software. Results were expressed as frequency and percent and mean with standard deviation (SD)

\section{RESULTS AND OBSERVATIONS}

Out of total 11500 pregnancies, 175 were ectopic pregnancy $(1.521 \%)$ with majority of the patients being in 21-30 years of age group (57.71\%)

Table-1

\begin{tabular}{|l|l|l|}
\hline & AGE DISTRIBUTION \\
\hline Age (Years) & Number & Percentage (\%) \\
\hline $18-20$ & 10 & 5.71 \\
\hline $21-30$ & 101 & 57.71 \\
\hline $31-40$ & 69 & 39.42 \\
\hline$>40$ & 5 & 2.87 \\
\hline TOTAL & $\mathrm{n}=175$ & 100 \\
\hline
\end{tabular}

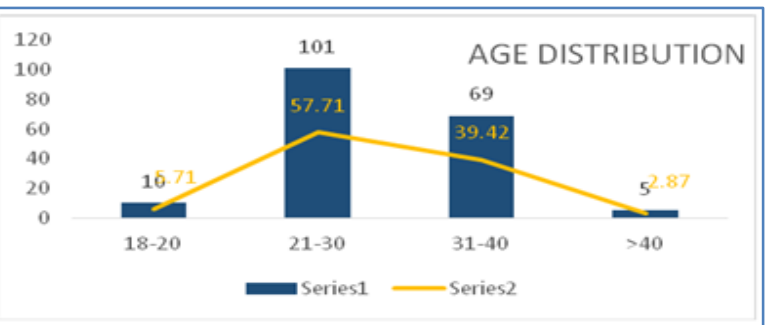

Fig-1

Table-2

\begin{tabular}{|l|l|l|}
\hline & \multicolumn{2}{|l|}{ PARITY WISE DISTRIBUTION } \\
\hline Parity & Number & Percentage (\%) \\
\hline 0 & 60 & 34.28 \\
\hline 1 & 38 & 21.71 \\
\hline 2 & 30 & 17.14 \\
\hline 3 & 22 & 12.57 \\
\hline$\geq 4$ & 25 & 14.28 \\
\hline
\end{tabular}

Most of the patients were nulliparous (34.28 $\%)$. There were presence of high risk factors in patientsmost common being history of miscarriage, ectopic pregnancy in the past, pelvic and or or abdominal surgery especially tubal surgery like tuboplasty and tubal ligation and caesarean section, history of pelvic inflammatory disease (PID) and history of intrauterine contraceptive device (IUCD).Many patients had more than one risk factors.

Table-3

\begin{tabular}{|l|l|l|}
\hline & HIGH RISK FACTORS PRESENT \\
\hline Variable & Number & Percentage (\%) \\
\hline H/O miscarriage $(\geq 1)$ & 75 & 40.0 \\
\hline Past history of ectopic pregnancy & 52 & 29.71 \\
\hline $\begin{array}{l}\text { Past pelvic-abdonimal surgery } \\
\text { Caesarean section } \\
\begin{array}{l}\text { Tuboplasty } \\
\text { Tubal ligation }\end{array}\end{array}$ & 43 & 24.57 \\
\hline History of PID & 38 & 21.71 \\
\hline History of IUCD use & 30 & 17.14 \\
\hline
\end{tabular}

Most of the patients were symptomatic - with 140 patients presenting with the classic triad of amenorrhea, abdominal pain and vaginal bleeding $(80 \%)$. Urinary pregnancy test was positive in all patients. In our study, the mean period of gestation at the diagnosis of ectopic pregnancy was 7 weeks 1 day.
Clinical diagnosis was made in 150 patients $(85.71 \%)$, while ultrasonographic diagnosis was made in 20 cases (11.4\%), 5 patients were diagnosed at laparoscopy $(2.85$ $\%$ ) and 2 patients were absolutely asymptomatic as depicted in table $3 \& 4$.

Table-4

\begin{tabular}{|l|l|l|}
\hline & \multicolumn{2}{|l|}{ CLINICAL PRESENTATION } \\
\hline Feature & Number & Percentage \\
\hline Asymptomatic & 2 & 1.14 \\
\hline Amenorrhoea & 169 & 96.57 \\
\hline Abdominal pain & 155 & 88.57 \\
\hline Vaginal bleeding & 98 & 56.00 \\
\hline
\end{tabular}




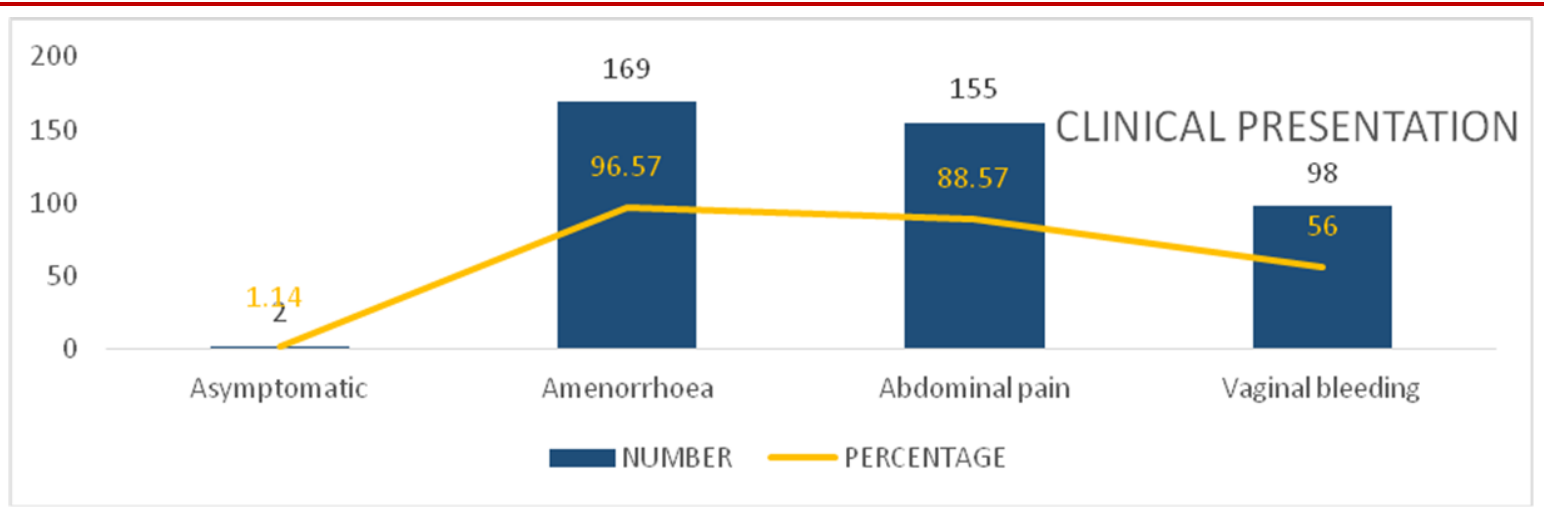

Fig-2

Table-5

\begin{tabular}{|l|l|l|}
\hline & \multicolumn{2}{|l|}{ DIAGNOSTIC MODALITY USED } \\
\hline Diagnostic Modality & Number & Percentage (\%) \\
\hline Clinical Examination & 150 & 85.71 \\
\hline USG & 20 & 11.40 \\
\hline Laparoscopy & 5 & 2.85 \\
\hline
\end{tabular}

\section{DIAGNOSTIC MODALITY USED}

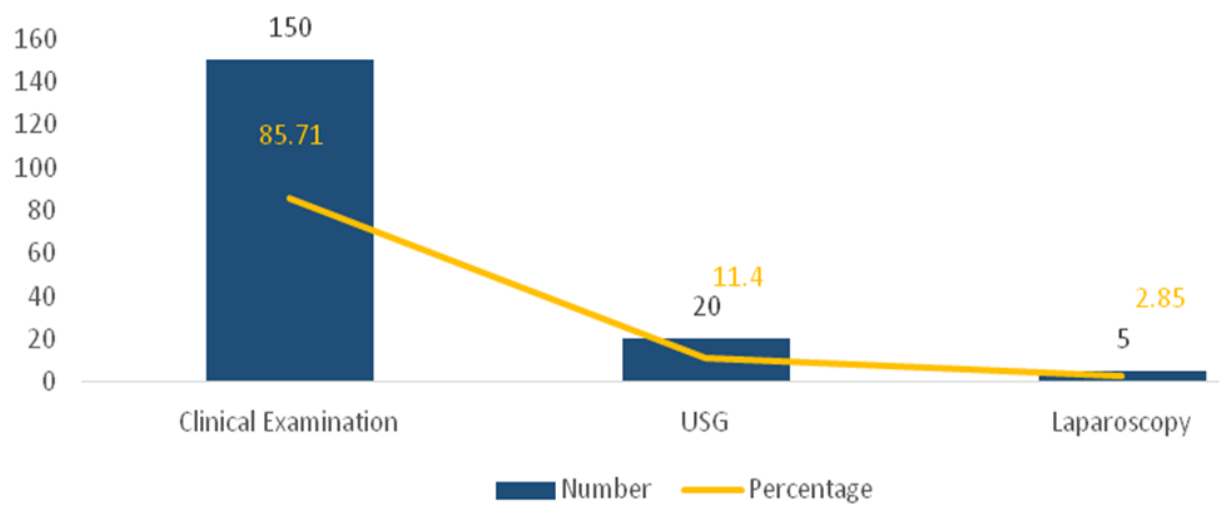

Fig-3

Table-6

\begin{tabular}{|l|l|l|}
\hline & \multicolumn{2}{|l|}{ SITE OF ECTOPIC PREGNANCY } \\
\hline Site & Number & Percentage $(\%)$ \\
\hline Tubal & 159 & 90.85 \\
\hline -Ampullary & 118 & 67.42 \\
\hline -Isthmic & 22 & 12.57 \\
\hline - Fimbrial & 19 & 10.85 \\
\hline Cervical & 2 & 1.14 \\
\hline Angular & 2 & 1.14 \\
\hline Unknown (PUO) & 12 & 6.85 \\
\hline Heterotropic & 2 & 1.14 \\
\hline
\end{tabular}




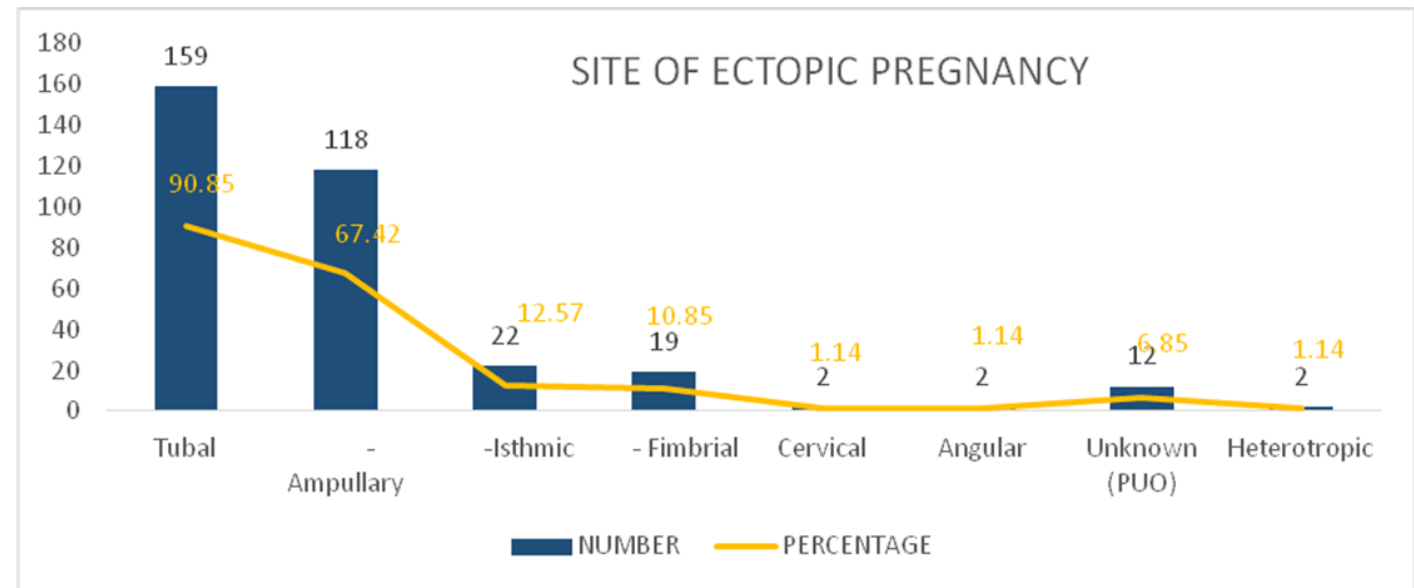

Fig-4

Fallopian tubes were the most common site of ectopic pregnancy $139 / 175$ with ampullary 118 , isthmic
22, fimbrial 19. Heterotropic pregnancy $2 / 175$ and pregnancy of unknown origin 12/175

Table-7

\begin{tabular}{|l|l|l|}
\hline & \multicolumn{2}{|l|}{ Clinical Signs } \\
\hline Signs & Number & Percentage (\%) \\
\hline Abdominal tenderness & 99 & 56.57 \\
\hline Cervical motion tenderness & 88 & 50.28 \\
\hline Fullness in adnexa/ POD & 56 & 32.00 \\
\hline Haemodynamic shock & 39 & 22.28 \\
\hline
\end{tabular}

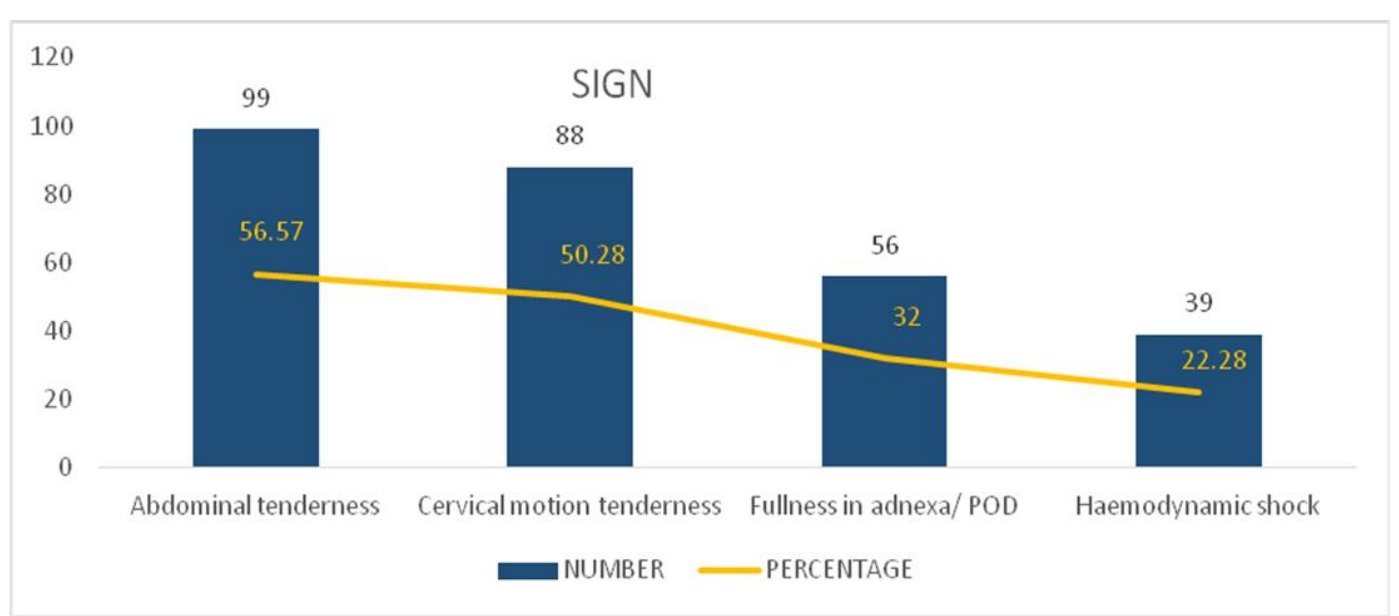

Fig-5

Table-8

\begin{tabular}{|l|l|l|}
\hline & \multicolumn{2}{|l|}{ MORBIDITY DISTRIBUTION } \\
\hline Morbidity variable & Number & Percentage (\%) \\
\hline ICU admission & 33 & 18.85 \\
\hline Surgical Site Infection & 11 & 6.28 \\
\hline Atelectasis & 2 & 1.14 \\
\hline Transfusion Related Acute Lung Injury (TRALI) & 4 & 2.28 \\
\hline Bowel Injury & 2 & 1.14 \\
\hline & & \\
\hline
\end{tabular}




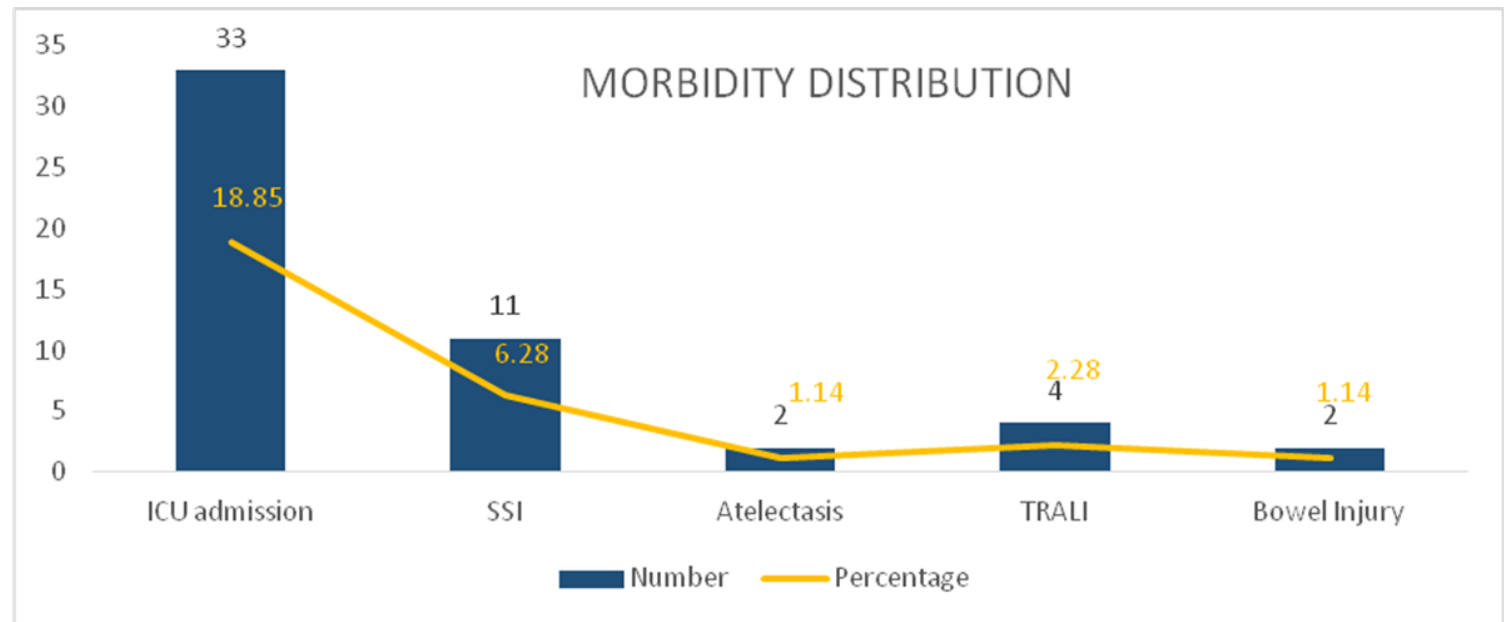

Fig-6

Mean hospital stay duration was $7 \pm 1.9$ days.

\section{DISCUSSION}

Ectopic pregnancy, an acute emergency, accounts for approximately 3.5-7.5\% of Maternal Mortality Rate (MMR) in India [1, 8, 9]. In our study, the incidence of ectopic pregnancy was 2.9/1000 deliveries. Other studies reported $0.56-1.95 \%$ incidence in developing countries and 2.5 to $4.9 \%$ in developed world [1-9, 10]. Among our patients, 85 (48.57\%) presented with classic triad of symptoms- amenorrhoea, pain in lower abdomen and bleeding per vaginum, whereas other studies reported as $28-95 \%$ of the same [1, 2, 12, 13]. Amenorrhoea was present in 169/175 cases $(96.57 \%)$. Urinary pregnancy test was positive in all patients. Singh et al. [2]- reported that $52 \%$ had no preceding amenorrhoea while Khaleeque et al. reported the mean gestational age at diagnosis to be 6weeks 1 day [3]. In our study, detailed history revealed at least one high risk factor in $80 \%$ patients (similar to those reported by other researchers [1-3, 14]. Previous pelvic surgery was the most common risk factor in $41 \%$ of our patients, followed by past history of miscarriages (40\%), previous ectopic pregnancy (29\%), PID (38\%) and use of IUCD (30\%). PId was cited as the most common risk factor in a study by Singh et al. (17.9\%) and previous tubal surgery by Mukti et al. (19.9\%) in their studies [1, 2, 16, 17]. Studies from Nigeria found PID in $27-36.6 \%$ of their ectopic pregnancy patients [4, $6,7]$. Although clinical diagnosis of ectopic pregnancy was possible in $150 / 175$ cases $(85.71 \%)$, but relying only on clinical examination would have led to missed diagnosis in approximately 25 cases $(14.28 \%)$.

USG diagnosis was made in $11.4 \%$ cases while 5 patients were diagnosed at laparoscopy (2.85 $\%$ ). Our results were comparable with those found in many other studies done in the Indian subcontinenet.

\section{CONCLUSION}

Ectopic pregnancy, an acute emergency, can result in considerable morbidity and mortality if diagnosis and management are delayed. We conclude that identifying common high risk factors and being ectopic minded, detailed history and thorough clinical examination with beta HCG test and USG pelvis will help clinicians in diagnosing and timely managing ectopic pregnancy at the earliest to reduce morbidity and mortality associated with the condition.

\section{REFERENCES}

1. Tahmina, S., Daniel, M., \& Solomon, P. (2016). Clinical analysis of ectopic pregnancies in a tertiary care centre in Southern India: a six-year retrospective study. Journal of clinical and diagnostic research: JCDR, 10(10), QC13.

2. Singh, S., Ghade, M. (2014). Clinical study of ectopic pregnancy in a rural setup. Natl J Med Res, 491:37-39.

3. Khaleeque, F, Siddiqui, R.I. (2010). A 3 year study on Ectopic pregnancy. J Pak Med assoc, 51(7):240242.

4. Udigwe, G. O., Umeononihu, O. S., \& Mbachu, I. I. (2010). Ectopic pregnancy: a 5 year review of cases at nnamdi azikiwe university teaching hospital (NAUTH) Nnewi. Nigerian Medical Journal, 51(4), 160.

5. Kirk, E., Bottomley, C., \& Bourne, T. (2014). Diagnosing ectopic pregnancy and current concepts in the management of pregnancy of unknown location. Human reproduction update, 20(2), 250261.

6. Jang, T.B. (2015). Pelvic sonography for diagnosis of ectopic pregnancy. J Ultrasound Med Off J Am Inst Ultrasound Med, 34(2):221-24.

7. Saranovic, M. (2014). Ectopic pregnancy and laparoscopy. Clin Exp Obstet Gynecol, 41(3):27679.

8. Cornelius, A. C., Onyegbule, A., Uchenna, E. T., \& Duke, O. A. (2014). A five year review of ectopic pregnancy at Federal Medical Centre, Owerri, South East, Nigeria. Nigerian journal of medicine: journal of the National Association of Resident Doctors of Nigeria, 23(3), 207-212. 
9. Taheri, M., Bharat, R. (2014). A UK national survey of trends in ectopic pregnancy management. J Obstret Gynecol, 34(6):508-11.

10. Ectopic pregnancy and miscarriage. (2014). NICE Quality standard. National Institute for Health and Clinical Excellence.

11. French, S., Henry, T., \& Williams, E. W. (2014). Evaluation of waiting times and sonographic findings in patients with first trimester vaginal bleeding at the university hospital of the West Indies. Can emergency department ultrasound make a difference?. The West Indian Medical Journal, 63(3), 247.

12. Horne, A. W., Shaw, J. L., Murdoch, A., McDonald, S. E., Williams, A. R., Jabbour, H. N.,
... \& Critchley, H. O. (2011). Placental growth factor: a promising diagnostic biomarker for tubal ectopic pregnancy. The Journal of Clinical Endocrinology \& Metabolism, 96(1), E104-E108.

13. Pal A. (2016). A study of high risk factors for ectopic pregnancy in Himachal Pradesh. J Indian Med Assoc, 94(5):172-73.

14. Mufti, S. (2012). Ectopic pregnancy: An analysis of 114 cases. JK- Pract, 17(4):20-23.

15. National Family Health Survey- 4(2016 Apr 19).

16. Baria, D., Thaker, R., Patel, M., Shah, S., Shah, P., \& Jani, S. (2013). Analysis of ectopic pregnancy at a tertiary care hospital: one year study. Int J Reprod Contracept Obstet Gynecol, 2(4), 621. 